Ensayo

\title{
El problema de la educación superior
}

\author{
The problem of Higher Education \\ Luis Armando González* \\ rluisgest@gmail.com \\ ISSN 1996-1642, Editorial Universidad Don Bosco, año 10, No.17, enero-junio de 2016, pp. 5-9 \\ Recibido: 4 de noviembre de 2015. Aprobado: 5 de enero de 2016
}

La dinámica y cambios en la universidad -y por ende, en la educación superior- es objeto de preocupación y reflexión a nivel mundial. En nuestro país, el polémico tema del mercantilismo educativo y su impacto en la educación superior ha sido abordado no de manera amplia y sistemática, pero sí con espíritu crítico. De hecho, cuando el asunto se tocó por primera vez no dejó de sonar a una herejía, pues se daba por hecho que el estilo de educación superior de la postguerra era el mejor que podíamos tener.

Se trata de un modelo empresarial, que ve al profesor (llamado "facilitador") como un empleado sometido a controles administrativos rígidos y con salarios bajos (sobre todo, si es un docente "hora clase"), y a los estudiantes como clientes que deben pagar por todo (por los "servicios educativos"), sin que eso suponga una mayor calidad en la educación que reciben.

El cultivo del saber, la reflexión, el análisis y la generación de conocimiento por la vía de la investigación prácticamente desaparecen del quehacer universitario, centrado en matrículas masivas, la permanencia de los alumnos (clientes) en la institución el mayor tiempo posible, la multiplicación de "grupos" (no asignaturas o materias) y el trabajo docente maquilizado.

Las carreras y profesiones no rentables dejan de ser importantes; y se promueven aquellas que a juicio de los administradores de las empresas universitarias son las demandadas por el mercado laboral real o virtual, o aquellas que pueden ser atractivas para las clientelas estudiantiles y sus familias.

* Licenciado en Filosofia por la Universidad Centroamericana José Simeón Cañas, maestría en Ciencias Sociales por FLACSO, México. 
Las humanidades y las ciencias sociales -y los profesionales que las cultivan- dejan de ser relevantes, con lo que se causa un daño imponderable en la calidad de la educación y de manera más amplia en la cultura, en el humanismo y en la ética. En nuestro país, en los años noventa, se gestó una lógica mercantilista perniciosa como la descrita, y de la cual no será fácil salir. Es imperioso hacerlo, eso sí, pues muchas cosas están en juego en la educación superior y su impacto en la sociedad.

Pero lo que se ha dicho no es exclusivo de nuestro país. Es un asunto que se debate también en Europa, tal como lo ponen de manifiesto Zygmunt Baumann y Leonidas Donskis en el libro Ceguera moral. La pérdida de sensibilidad en la modernidad líquida (Paidós, México, 2015), en el cual dedican un capítulo precisamente al tema de la universidad. El capítulo se titula: "Arrasar la universidad: el nuevo sentido del sinsentido y la pérdida de criterios".

Y los autores formulan de esta manera su planteamiento inicial:

La cuestión relativa a si la universidad sobrevivirá al siglo XXI como una institución clásica reconocible de educación y erudición ya no parece ni ingenua ni incorrectamente formulada... observando lo que sucede hoy en Europa y especialmente en Gran Bretaña está más que justificado sopesar las estrategias intelectuales para el futuro. ¿Qué hacemos? ¿Mirar cómo las universidades mueren lentamente o crear algunas alternativas que durarán más que los pocos mandatos que los políticos pasan en el Parlamento o el Gobierno? (p. 170).

La transformación, que pone en vilo la sobrevivencia de la universidad tal como esta se configuró históricamente, inició con el gobierno de Margaret Thatcher que desmanteló -apuntan los autores- el viejo sistema académico británico. Es extraña, anotan,

la importación de este proceso a Europa. Durante muchos años el sistema académico finés (...) era muy envidiado por colegas de otros sistemas académicos europeos. Hoy todo ha cambiado, y Finlandia ha incorporado un híbrido de los modelos estadounidense y británico, cuya idea general es la misma: consigue el dinero por ti mismo, sin ayuda del Estado o incluso de la universidad. (p. 170).

Y más adelante, añaden:

Imitando a las universidades privadas y a las escuelas de administración de las empresas estadounidenses en particular, los burócratas y los políticos de Gran Bretaña y de la Europa continental han adoptado una jerga empresarial que recuerda a la neolengua orwelliana para la gestión universitaria modelaba según el patrón de una corporación empresarial; y los más triste de todo, con ello respaldan la lógica de los resultados y logros rápidos. (p. 171). 
El impacto nocivo que esto tiene es evidente:

En esencia, una universidad, que se supone sigue una lógica de pensamiento deliberado (fielmente observado durante siglos), creatividad pausada y existencia equilibrada, hoy en día se ve obligada a transformarse en una organización que reacciona rápidamente a las fluctuaciones del mercado así como a los cambios en la opinión pública y el entorno político. Es el precio que pagamos por una educación superior de las masas en una democracia de las masas y una sociedad de masas. (p. 171).

Se ha trasplantado la lógica mercantil a la lógica del conocimiento y la cultura. El sinsentido no puede ser más palmario:

Tal vez la lógica de consumo rápido y la reacción instantánea permitió la formación de criterios de eficacia en las fábricas, los talleres, las empresas y los almacenes de la era industrial, pero transferidas a las universidades y los institutos de investigación de la era postindustrial de la información, esta lógica es grotesca y absurda. Es posible alcanzar resultados rápidos en sistemas sencillos o trabajar en la educación popular, pero la investigación realmente importante, los proyectos fundacionales y las humanidades y las ciencias sociales, que cambian el mundo de las ideas no pueden -a diferencia de las aplicaciones de la tecnología y la cultura popular- desarrollarse rápidamente y entregarse al consumo rápido, sencillamente porque su preocupación básica tiene que ver con escuelas de pensamiento y con procesos autocorrectores que no pueden consumirse en unos días. (p.171)

En fin, el cultivo del conocimiento, natural y humano-social, no es algo que debe someterse a la lógica mercantil-empresarial, porque esta lo termina aniquilando. Lo mismo que la investigación científica en sus distintas concreciones. Aquí, la ruta más corta es una trampa. En educación superior -si se la toma como lo que debe ser- no hay manera de evitar el camino de la complejidad y la problematización. No hay forma de quemar etapas, y poner la carreta delante de los bueyes termina por ser una costosa ficción.

Qué quiere decir eso de "poner la carreta delante de los bueyes" en educación superior. Desde el punto de vista de quien esto escribe, poner la carreta delante de los bueyes en educación superior significa pretender que las fallas educativas se superarán a partir de la potenciación (multiplicación) de grados superiores (maestrías y doctorados) sin elevar la calidad (incluso manteniendo en el descuido) los bachilleratos y, principalmente, las licenciaturas. Es decir, creyendo que si tenemos maestros y doctores suficientes, por un efecto de cascada, el sistema de educación superior, de pronto, va a dejar de ser lo que es en su baja calidad.

Es válido pensar que a más maestros y doctores mayor desarrollo de la educación superior; es decir, más aportes teóricos, investigativos y contribuciones 
al conocimiento científico, filosófico y literario. Hay varias cosas que quedan en el tapete de la discusión, y que se soslayan a veces con ingenuidad.

Uno, la calidad de los maestros y doctores, o sea, si el grado obtenido en realidad es un grado merecido. No se trata de la validez del título o las buenas notas, sino si el aporte académico de esos graduados, antes de culminar sus estudios y después - a lo largo de su trayectoria posterior- avala ese grado, o sencillamente se trató de un esfuerzo que culminó nada más con un título en la pared. Los grados académicos obligan, suponen una responsabilidad cognoscitiva y ética.

Dos, la producción real (investigaciones, ensayos, reflexiones, docencia) de los maestros y doctores ise corresponde con su peso numérico? Es decir, lo lógico sería esperar que, a medida que aumentan las personas con esos grados, aumente la producción académica en un país, que además debería ser de calidad -en consonancia con la responsabilidad que tienen quienes gustan ser llamados "maestros" o "doctores". Lo que sucede en nuestro país no da lugar al optimismo: se tienen más maestros y doctores (y doctoras) que nunca, pero la producción académica no se corresponde con esos numerosos graduados. Algo está pasando y es importante explorarlo.

Tres, la calidad de la formación recibida. Ostentar un grado de maestro o doctor supone contar con méritos académicos que van más allá de haber aprobado los requisitos de graduación, pues esos méritos deben ser probados (y acrecentados) en la práctica de manera constante una vez que se obtiene el título. Le vida académica no es flor de un día; requiere dedicación, disciplina y creatividad. Es avalada por las contribuciones permanentes al saber, no por las elaboraciones accidentales o, peor aún, por la mera pose.

Cuatro, las maestrías y los doctorados no deben servir para remediar las deficiencias, los vacíos o las debilidades de los grados previos, principalmente de la licenciatura. Hay una secuencia perversa que es necesario romper y es esta: la licenciatura se ha convertido un remedio para el bachillerato, esto es, en una continuación del mismo; la maestría en un remedio para la licenciatura (de suerte que alguien con maestría termina siendo un regular o buen licenciado por lo que sabe y conoce) y los doctorados en un remedio para las maestrías (algunos doctores son en realidad maestros, por lo que saben y producen).

Quinto, el bachillerato y la licenciatura son el fundamento de la educación superior. Un sólido bachillerato asegura que la licenciatura sea esa base firme para afianzar saberes y prácticas que deberían servir para el desarrollo profesional y personal de quienes la obtienen.

Por una deformación mercantilista, la licenciatura dejó de verse como algo básico (en el sentido de base) para entenderse como algo básico en el sentido de elemental. La licenciatura debe ser lo más sólida posible (lo mismos que las

El problema de la educación

8. superior 
deficiencias graves (como no poder entender un texto o redactar un informe o un ensayo) que no se superaron en la licenciatura (y que vienen del bachillerato o de más atrás). Lo mismo vale para las maestrías en relación con los doctorados. A la solidez de la licenciatura, se aúna la recuperación de su prestigio, que hoy por hoy se ha perdido. Una licenciatura rigurosa, firme, que se avale por la capacidad de los licenciados para desempeñarse en una profesión aportando conocimientos y prácticas creadoras, sería bien reconocida laboralmente, sería -como en otros tiempos- fuente de prestigio.

Y sexto: ¿Qué pasa con las maestrías y doctorados? Hay que recuperar su sentido propio: son caminos para la especialización académica (maestrías) y para la contribución al saber (doctorados). Nadie está obligado a ser doctor o maestro, si no tiene la vocación o el interés académico correspondiente. Nadie debería aspirar a esos grados para superar fallas elementales de su formación previa o para obtener mejores ingresos (a veces notablemente mejores) dado el descrédito de la licenciatura. Ambas visiones empobrecen el carácter de esos grados académicos y hace que aspiren a ellos quienes no tienen la menor idea de la responsabilidad que tal cosa supone.

En definitiva, hay que defender el fortalecimiento de las licenciaturas como pieza fundamental de la educación superior. Es razonable pensar que sin ese fortalecimiento -que supone dar solidez a los bachilleratos- nuestro país no va a superar sus graves problemas a nivel de educación superior. Hay que ver la licenciatura como un fin en sí mismo; como lo máximo a lo que se puede aspirar en educación superior, pues si se la ve así se dedicará los mejores recursos para ese tramo formativo que será, para la mayoría de los pocos que realizan estudios superiores, el último al cual accedan.

La idea de que siempre habrá más educación -siempre que se pueda pagares propia de una visión mercantilista nociva para avanzar en el conocimiento. Más realista es la idea de que lo que se recibe en educación, en un momento determinado, es lo último que se tendrá y, por tanto, hay que sacarle el máximo provecho. Así es como debería verse la licenciatura. 